'||||||||||||||||||||||||||||||||||||||||||||||||||||||||||.

\section{Constant Dripping}

nownerate

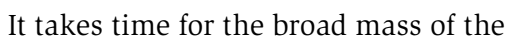
population to become fully aware of unpleasant truths. On the other hand, the shouting is unlikely to subside until people finally realize that thinking before you act is better than jumping in with both feet.

One of the very vocal arguments that has been put forward is a call for a ban on all vehicles with combustion engines and their replacement with electric equivalents. The mistaken belief that battery electric vehicles produce no emissions is still widespread. The assumption that synthetic fuels can be burnt without releasing $\mathrm{CO}_{2}$ into the atmosphere, in other words that they can be decarbonized, is equally incorrect. The only fuel that contains no carbon is hydrogen.

The reality is that transport will always produce emissions, regardless of which route we decide to take. However, it is conceivable that a closed $\mathrm{CO}_{2}$ circuit could be established. This would mean releasing no more fossil-based $\mathrm{CO}_{2}$. The amounts of energy that would be needed are enormous. In addition, the energy would have to be widely available and carbon-neutral. In the first step, hydrogen would be produced using electrolysis. This would then be converted into hydrocarbons by adding $\mathrm{CO}_{2}$ from the air.

For major emitters, such as the shipping and aviation industries in particular, there is unlikely to be any alternative to synthetic fuels. However, the amounts of fuel required are so eye-wateringly large that every month of delay in establishing the production capacity is causing harm. Trucks and cars could also benefit from these fuels and make a contribution to achieving the climate goals.
As things currently stand, the opposition in the German parliament is not prepared to recognize this approach. They are either demanding bans and the introduction of electric vehicles without looking at the real emission figures or calling for vehicles that only offer the option of running on e-fuels to be regarded as the equivalent for tax purposes of BEVs, which would mean that all the vehicles currently on the roads would be exempt from tax. This almost childlike naivete will ultimately only lead us up blind alleys and we need to avoid this at all costs.

The only solution here is the constant dripping that wears away a stone. We need technology neutrality and not a narrow-minded, dogmatic approach. We need to move heaven and earth rather than just making minor adjustlikely be expensive.

I do hope you enjoy this issue of MTZ.

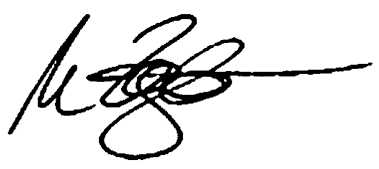

Marc Ziegler

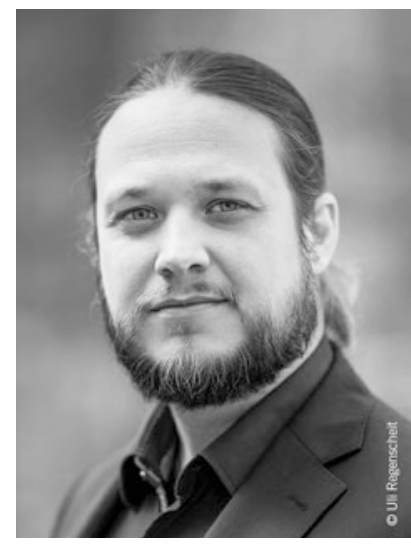
ments. Oh, yes - and all of this will

Deputy Editor in Chief 